\title{
Architecture and life forms of Thymus jenisseensis (Lamiaceae)
}

\author{
Evgeniya B Talovskaya ${ }^{1 *}$, Irina $\mathrm{N}$ Barsukova ${ }^{2}$, and Natalia Yu Kurochkina ${ }^{1}$ \\ ${ }^{1}$ Central Siberian Botanical Garden of the SB RAS, 630090 Novosibirsk, Russia \\ ${ }^{2}$ Katanov Khakass State University, 655017 Abakan, Russia
}

\begin{abstract}
Thymus jenisseensis is endemic to Southern Siberia. The structure of Thymus jenisseensis were studied with the use of an architectural approach. The architectural unit consist of branched compound skeletal axis of the $1^{\text {st }}$ and $2^{\text {nd }}$ order, and is repeated many times in the structure of adults. As a result of studying the architectural units of individuals growing in different sites of a coenopopulation, in the upper border of the forest belt (Tsagan-Shibetu, Republic of Tuva), differences were identified. An architectural unit consisting of branched orthotropic or ascending basisympodially accreting compound skeletal axes develops on a site of a dry riverbed; an architectural unit consisting of branched orthotropic or ascending acrosympodially accreting compound skeletal axes develops on a site of high-altitude steppe on a plain. The diversity of compound skeletal axes in the structure of architectural units contributes to the formation of two biomorphs (dwarf subshrub and dwarf shrub), changes in the vitality and duration of development of $T$. jenisseensis individuals. The identified features of architecture are morphological mechanisms of adaptation of the species to living conditions.
\end{abstract}

One of the modern approaches to studying taxonomically complex groups of plants is to identify architectural units in their structure. An architectural unit is a basic structural and functional unit of a particular type that contains a complete set of all hierarchically subordinate structures and is repeated in the overall architecture of a plant. The characteristics of the architectural unit of each plant species are constant and change only quantitatively depending on the growing conditions $[1,2]$.

In this regard, the species of the genus Thymus are of interest. Previously, the dwarf shrubs Thymus dmitrievae Gamajun., T. petraeus Serg., Thymus vulgaris L. and others were studied from the position of architectural approach [3-5]. The article is devoted to the study of endemic to Southern Siberia T. jenisseensis Iljin. The range of the species covers the plain-steppe and mountain-steppe regions of Southern Siberia (Fig. 1a). In the forest belt, the species growth the rocky outcrops of coastal slopes and riverine sands.

The analysis of the literature, herbarium collections (LE, NS, NSK, TK) and our own collections showed that throughout the range of $T$. jenisseensis, the life form of the dwarf subshrub prevails $[6,7]$. The aim of the work is to study the architecture of T. jenisseensis to identify mechanisms of its adaptation to habitat conditions.

\footnotetext{
*Corresponding author kolegova e@mail.ru
} 
The study was conducted on the territory of the Republic of Tuva, Tsagan-Shibetu, Barlyk river valley, in the upper border of the forest belt. The material is collected in two sites of a coenopopulation (SCP): 1 - the dry riverbed, individuals of a species were located on sandy substrate among the pebbles; 2 - the high-altitude grass steppe on a plain, individuals of a species were located on soil among the outcrops of stones (Fig. 1b).
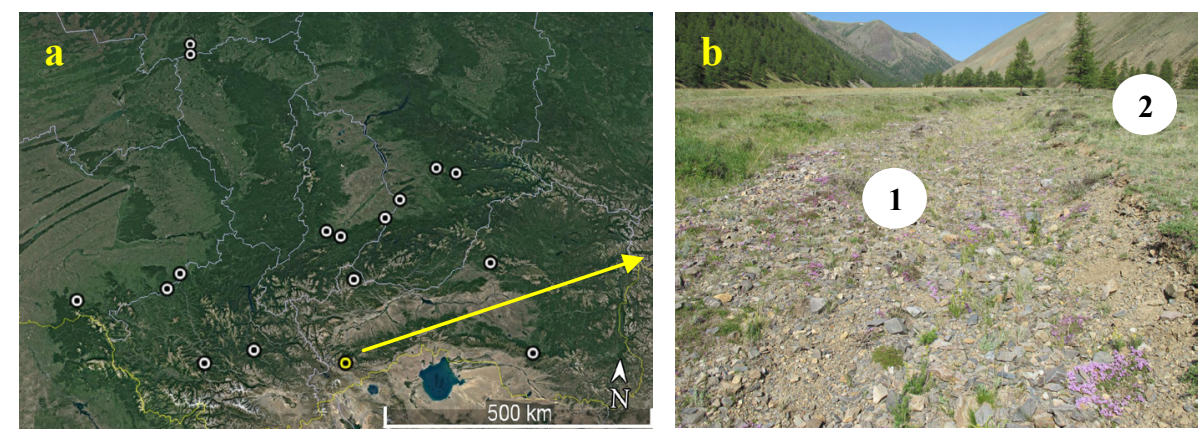

Fig. 1. The area of Thymus jenisseensis in Siberia ( $\mathrm{a}$ - the location of the species, $\mathrm{b}$ - the studied coenopopulation: 1 and 2 are sites of a coenopopulation).

The life form of $T$. jenisseensis was determined with the use of ecologicalmorphological classification of life forms by I. G. Serebryakov [8]. When describing a shoot system was used the approach of M. T. Mazurenko and A. P. Khokhryakov [9] based on the role of shoots in a bush structure.

Individuals of $T$. jenisseensis have a branched compound skeletal axis (CSA). A compound skeletal axis is a combination of formation shoots appearing as a result of monopodial-sympodial accretion. The branched CSA of the 1st order is the basis for the development of branched CSA of the 2nd ordeis, biannual branching shoots, and ephemerous shoots.

According to the concept architecture of plant [1,2], the architectural unit of $T$. jenisseensis consists of branched CSA of the 1st and 2nd order (Fig. 2).

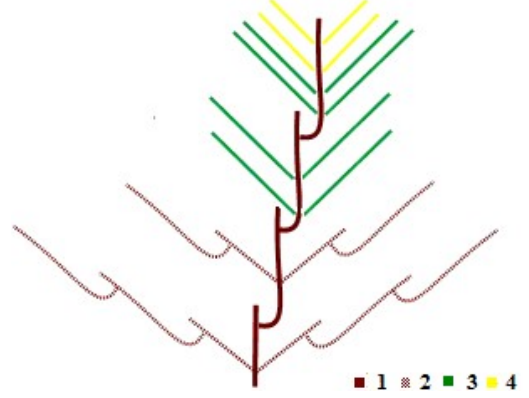

Fig. 2. Structure of the architectural unit Thymus jenisseensis (1 - branched compound skeletal axis of the 1st order, 2 - branched compound skeletal axis of the 2 nd order (side shoots are not shown) 3 biannual branching shoots, 4 - ephemerous shoots).

Analysis of individuals of T. jenisseensis has shown that their structure is formed by repetition of the architectural unit. It was found that branched CSA differ in the method of growth (acro-, basisympodial) and position in space (orthotropic, ascending).

In SCP 1 in the dry riverbed, where in winter the snow cover is delayed, the architectural unit consists of branched orthotropic or ascending basisympodially accreting CSAs. These branched CSAs take root on the sandy substrate, grow for about 5 years and form the perennial base of the bush. All shoots and axes consist of long metamers. 
Individuals are characterized by high vitality: the diameter of the bushes is $56.4 \pm 0.8 \mathrm{~cm}$, the length of the ascending CSA is $28.2 \pm 0.6 \mathrm{~cm}$, the number of generative shoots is $87.4 \pm 0.9$ pcs, the length of generative shoots is $5.2 \pm 0.4 \mathrm{~cm}$. In the structure of an adult individual, on average, there are 5.3 \pm 0.3 architectural units with ascending CSAs and 3.6 \pm 0.5 - with orthotropic ones. The life form of a vegetative-semimobile dwarf subshrub is formed. The plant is a clump consisting of primary bush and partial bushes.

In SCP 2 in the high-altitude grass steppe on a plain, the habitat conditions of $T$. jenisseensis individuals are characterized by strong weathering, lack of snow cover and dryness. The architectural unit consists of branched orthotropic or ascending acrosympodially accreting CSAs. These branched CSAs do not take root, grow up to 15 years. All shoots and axes consist of short metamers. Individuals are characterized by reduced vitality: the diameter of the bush is $20.5 \pm 1.1 \mathrm{~cm}$; the length of the ascending CSA is $15.7 \pm 0.4 \mathrm{~cm}$; the number of generative shoots is $56.3+5.6 \mathrm{pcs}$, the length of generative shoots is $1.6 \pm 0.2 \mathrm{~cm}$. The structure of an adult individual is dominated by architectural units with orthotropic CSAs of $4.7 \pm 0.4$; the number of architectural units with ascending CSAs is $1.6 \pm 0.2$. The life form of a vegetative-immobile dwarf shrub is formed.

The study showed that in the conditions of the upper border of the forest belt on the Tsagan-Shibetu ridge (Republic of Tuva) in different sites of the cenopopulation, the architectural unit of $T$. jenisseensis differs in the features of a compound skeletal axis. This leads to the formation of two biomorphs (dwarf subshrub and dwarf shrub), changes in the vitality and duration of development of $T$. jenisseensis individuals. The identified architectural features are mechanisms of adaptation of the species to habitat conditions, and demonstrate the range of morphological plasticity of $T$. jenisseensis in the coenopopulation.

The work was carried out with the financial support of the grant of RFBR within the framework of scientific project № 18-04-00621-a and project of the State Assignment of Central Siberian Botanical Garden of the Siberian Branch of the Russian Academy of Sciences № AAAA-A17-117012610053-9.

\section{References}

1. D. Barthélémy, Y. Caraglio, Annals of botany 99, 375-407 (2007).

2. C. Edelin, Forest Research Institute Malaysia Research Pampblet 105, 1-222 (1990).

3. E. B. Talovskaya, V. A. Cheryomushkina, I. N. Barsukova, Contemp. Probl. Ecol. 13, 85-94 (2020).

4. M. Millan, N. P. Rowe, C. Edelin, Flora 251, 1-10 (2019).

5. V. Cheryomushkina, E. Talovskaya, A. Astashenkov, Biharean biologist 13, 61-65 (2019).

6. M. V. Klokov, Thymus L. Flora SSSR (AN SSSR, Moscow, Leningrad, 1954).

7. A. S. Prokopyev, T. N. Kataeva, E. Yu. Machkinis, Rastitelnye resursy 52, 239-254 (2016).

8. I. G. Serebryakov Ekologicheskaya morfologiya rasteniy (Moscow, 1962).

9. M. T. Mazurenko, A. P. Khokhryakov, Structure and morphogenesis of shrubs (Moscow, 1977). 